\title{
Is Enjoyment Still Important in University Second Language Education?
}

\author{
Junko Winch \\ Imperial College London \\ Sherfield Building, Level 3, South Kensington Campus \\ London SW7 2AZ, United Kingdom
}

Tel: 0-1722-320-359Ｅ-mail: j.winch@imperial.ac.uk

Received: August14, 2017 Accepted: September 1, 2017 Published: September 7, 2017

doi:10.5296/gjes.v3i2.11691

URL: https://doi.org/10.5296/gjes.v3i2.11691

\begin{abstract}
This study investigates if undergraduate students majoring in Science, Technology, Engineering and Medicine (STEM) who have studied Japanese in the Institution-Wide Language Provision (IWLP) context experienced enjoyment in Japanese language learning. This research was held at a British STEM university in London. Questionnaires were used to generate the quantitative and qualitative data. The participants were STEM undergraduate students who were studying Japanese in the 2015/16 academic year. The results showed that the majority of students experienced enjoyment and flow in Japanese language learning. These results show that the general assumption that all learning is grim and unpleasant is not necessarily true and that the assumption may be changed. Furthermore, language learning may be considered as the same as a leisure activity such as games, shopping or hobbies. As an implication for professional practices, language teachers are encouraged to be familiar with the concept of enjoyment and flow so that they are able to manipulate to invoke students' enjoyment and flow.
\end{abstract}

Keywords: Enjoyment, Flow, IWLP, Japanese language learning, STEM 


\section{Introduction}

This study investigates Science, Technology Engineering and Medicine (STEM) students' Japanese language learning at Imperial College London in 2016, where Japanese was taught in an Institution-Wide Language Provision (IWLP) context. STEM and IWLP are explained below.

STEM is highlighted in this study because it is claimed that STEM and non-STEM subjects require different pedagogical disciplines and that these differences may influence students' logical thinking, learning preferences and learning priority. According to Neumann, Parry \& Becher (2002), disciplines are broadly categorised into four, that is, hard pure, soft pure, hard applied and soft applied. Physics and chemistry are categorised as "hard pure", history and anthropology are examples of "soft pure". Engineering typifies a "hard applied" discipline, whereas education and management studies are examples of "soft applied" discipline. The difference between "hard" or "soft" in the "pure" category is broad whether the emphasis is on quantitative (hard) emphasis or qualitative (soft) (Neumann et al., 2002, p. 406) and whether the knowledge is concerned with universals or with particulars (Neumann, Parry \& Becher, 2002, p. 406), etc. Furthermore, the objective of test assessments in the hard disciplines is knowledge acquisition, whereas in that of soft disciplines it is the level of sophistication of understanding and interpretation and judgement (Young, 2010). Differences between "pure" and "applied" is that "applied" is "drawing on hard pure knowledge and application" (Young, 2010) of products, technique or professional practices. It is possible to say that STEM students of this study consist of hard pure and hard applied disciplines based on Neumann, Parry and Becher (2002) classification. The study of specific STEM students is significant in that it is relatively difficult in language studies to collect only STEM undergraduate students.

IWLP is defined "typically comprises elective language course units taken from academic credit and language courses studied in addition to and alongside a student's degree programme" (Association of University Language Centre (AULC), 2016, p. 2). It benefits both students and language teachers. IWLP has allowed non-language majoring undergraduate students to study languages on an accredited or non-accredit basis. For those who are involved in language teaching, IWLP also benefits an increase in the number of non-language major students who wish to study language and therefore promoting language learning.

IWLP is a good indicator to show students' preferences on their language and learning priority. Taking note that studying another language in addition to students' STEM major subject requires the students' additional commitment, studying Japanese language puts students under extra academic pressure and work such as memorising vocabulary, phrases, sentence structures, etc. for assessment. If students do not truly enjoy language learning, particularly, STEM students who study languages in an IWLP context would soon lose interest and drop out as they do not need to study Japanese after all. STEM students' learning priority is not often researched in language learning studies at higher education. In this respect, this study is significant as the focus of the specific IWLP and STEM context enables 
to uncover the students' true enjoyment of learning clearly.

From the above discussion, the hypothesis was created that STEM majoring students study Japanese because they enjoy learning. However, this hypothesis contradicts from the general assumption that 'all learning is accompanied with pain' (Davidson, 1990, p. 201) and "at present...-schools, officers, factories are organised around the assumption that the serious work is grim and unpleasant" (Csikszentmihalyi, 1977, p. 1). What is the enjoyment that STEM students experience, disregarding these general assumptions?

\section{Theoretical Framework}

2003 and 2008 UK government policy texts highlighted the notion of enjoyment. Over a decade has passed and those who received the education of enjoyment and learning in primary education are now undergraduate students or older. For those who have been brought up with the enjoyment in learning expect enjoyment? In other words, is enjoyment still important in the second language learning at university? To explore this question, this section starts with the definition of enjoyment, which is followed by introduction of a few characteristics of enjoyment and the mechanism of enjoyment.

\subsection{Definition of Enjoyment}

As enjoyment and pleasure are synonyms and used almost interchangeable in daily life, comparing these two terms may enable us to define the enjoyment. Csikszentmihalyi (1977) defines pleasure as "the satisfaction of basic needs - hunger, sex and so forth... in the present model, it does not require the use of complex skills" (Csikszentmihalyi, 1977, p. 54). Csikszentmihalyi (1977) also points out a pleasure/enjoyment continuum ranging from repetitive, automatic acts (chewing gum) to complex activities which requires the full use of a person's physical and intellectual potential. Based on Csikszentmihalyi's (1977) notion of this "pleasure/enjoyment continuum", in this paper, enjoyment can be defined as non-repetitive automatic acts and involves more complex activities which requires the full use of person's physical and intellectual potential. In addition to this, Blunsdon, Reed, and McNeil (2003) definition of enjoyment may also be added: "enjoyment is sometimes called 'interest' or 'expressed liking” (Blunsdon, Reed \& McNeil, 2003, p. 44). In order to assess STEM students' enjoyment of their language learning, the following question is asked to analyse students' data: Do students make any comments associated with interest and express their liking?

\subsection{High Arousal Positive States (HAP) and Low Arousal Positive States (LAP)}

Enjoyment has a few characteristics. First one is HAP and LAP states. Enjoyment consists of high and low arousal positive states (Tsai, Knutson \& Fung, 2006). HAP states are associated with "enthusiastic, excited, energetic" (Tsai, Knutson, \& Fung, 2006, p. 290) and "joy" (Kuppens, 2008, p. 1054), whereas LAP states are associated with "calm, relaxed, serene" (Tsai, Knutson \& Fung, 2006, p. 290) content (Kuppens, 2008, p. 1054) and "at ease" (Kuppens, 2008, p. 1057). This means that enjoyment is perceived differently by individuals. In other words, "for some individuals feeling enjoyment usually implies feeling excited and enthusiastic, whereas for others feeling enjoyment usually implies feeling relaxed and at 
ease" (Kuppens, 2008). These individual differences in feeling enjoyment is claimed to be cultural specific. According to Tsai, Knutson and Fung (2006), 'individuals from individualist culture (e.g. American, British and Australian culture, etc.) seem to prefer and value HAP (e.g. enthusiastic, excited, energetic) and individualist from collectivist culture (e.g. Chinese and other East Asian cultures) seems to prefer and value LAP (e.g. calm, relaxed, serene)' (Tsai, Knutson \& Fung, 2006). Individualist culture is defined as "the tendency to place individual over group concerns" (Tsai, Knutson \& Fung, 2006, p. 290), and collectivist cultures as 'the tendency to place group over individual concerns' (Tsai, Knutson, \& Fung, 2006, p. 290). The current learning environment became globalized and university students consist of both individualist and collectivist cultures and the participants in this study also include both cultures. Therefore, it is essential that language teachers invoke both HAP and LAP states to meet students' preferences and requirements from both cultures. Whether STEM students in this study experience either HAP or LAP is part of the investigation of students' enjoyment.

\subsection{Trait Emotions and State Emotions}

The second characteristic of enjoyment is trait emotions and state emotions (Goetz et al., 2006). "Trait emotions are built over time" (Lumby, 2011, p. 7) and are experiences of cumulative enjoyment. "State emotions are experience in the present, the current enjoyment" (Lumby, 2011, p. 7). According to Blunsdon, Reed \& McNeil's (2003) study, "students are more willing to act on their feeling for the moment...enjoyment is experienced at the moment, while learning often occurs over a long period of time and one's appreciation of the learning experience (cognition) might occur at a much later point in time" (Blunsdon, Reed \& McNeil, 2003, p. 52). This suggests that students usually experience state emotions first before they may experience trait emotions. These two types of emotions are also associated with experiential and reflective cognition (Rieber \& Noah, 2008). "Experiential cognition is based on reactions to moment-to-moment event" (Rieber \& Noah, 2008, p. 80) whereas "reflective cognition requires careful and deliberate though and consideration over time" (Rieber \& Noah, 2008, p. 80). Obviously, state emotions work with experiential cognition and trait emotions work with reflective cognition. Whether STEM students from this study experience either trait emotions or state emotions are also part of the investigation of students' enjoyment.

\subsection{The Mechanism of Enjoyment}

According to Lumby (2011), enjoyment is triggered by the following four elements: i) flow experience; ii) cessation of anxiety control; iii) satisfaction; and iv) security of belonging. Among these four, the first point, flow experience, should be taken note of. According to Csikszentmihalyi (1977) who created the flow concept, flow is defined as 'the holistic sensation when people they act with total involvement' (Csikszentmihalyi, 1977, p. 36). Lumby's (2011) first point suggests that flow is an antecedent of enjoyment. In other words, people usually experience flow first, before they experience enjoyment. This claim shares a similar view with Csikszentmihalyi's (1977) as he claims that "flow experience... is the crucial component of enjoyment" (Csikszentmihalyi, 1977, p. 11). However, there is also a different view. Shernoff et al. (2003) claim that "concentration, interest and enjoyment must 
be experienced simultaneously in order for flow to occur" (Shernoff et al., 2003, p. 161). This implies that enjoyment is antecedent of flow, which is the opposite claim of Lumby (2011) and Csikszentmihalyi (1977). In this study, STEM students are assessed whether their enjoyment is with or without the presence of flow so that it may be able to determine whether flow is an antecedent of enjoyment or not.

\section{Methodology}

\subsection{Instrument}

This research uses both quantitative and qualitative methods using the researcher's questionnaires. The data was analysed in two ways. Firstly, the descriptive statistics derived from questionnaires experiencing enjoyment and flow was used. Secondly, content analysis was carried out from those who left comments in the open-ended questions regarding why STEM students study Japanese and regarding enjoyment and flow experience. From this, a range of themes were discerned from the analysis of the individual comments. These similar emerging themes were grouped together and then cross-referenced with the concept of enjoyment and flow to interpret the data. Exploring the questionnaire data allowed exploring the concepts of enjoyment and flow uncovered through Japanese language learning.

Students' enjoyment was investigated by two questions: a) a direct question, 'Is learning fun?' and b) an indirect question, 'Do you wish to continue learning Japanese after this course? If so why?' The questions were asked directly and indirectly due to one of the weaknesses of the questionnaires, which is 'there are discrepancies between what people say that they have done, or will do and what they actually did or will do' (Robson, 1993, p. 191).

According to the Theory of Planned Behaviour (Ajzen, 1991) and Theory of Reasoned Action (Fishbein \& Ajzen, 1975), "behavioural intention can be a strong predictor of actual behavior" (Koufaris, 2002, p. 207). Koufaris (2002) also claims that 'intention to return' is a satisfactory approximation of actual customer retention' (Koufaris, 2002, p. 207). Using this theory, 'intention to return' may also indicate STEM students' enjoyment in Japanese learning.

With regards to whether STEM students' enjoyment is trait or state emotion, students were asked to tick either statement a) the enjoyment of Japanese was the experience of a specific class or statement b) the enjoyment of Japanese was the cumulative experiences, built over time.

Whether students experienced HAP or LAP, students were asked to tick the applicable emotions they experienced from the list of emotions which belong to HAP or LAP. HAP was associated with emotions such as "enthusiastic, excited, energetic" (Tsai, Knutson \& Fung, 2006, p. 290) and "joy" (Kuppens, 2008, p. 1054). LAP was associated with emotions including "calm, relaxed, serene" (Tsai, Knutson \& Fung, 2006, p. 290), "content" (Kuppens, 2008, p. 1054) and "at ease" (Kuppens, 2008, p. 1057).

STEM students' experience of flow was investigated using one of Csikszentmihalyi's (1977) seven conditions. These seven conditions are: 1) merging of action and awareness 
(Csikszentmihalyi, 1977, p. 38); 2) the tasks are within one's ability to perform (Csikszentmihalyi, 1977, p. 39); 3) centering of attention (Csikszentmihalyi, 1977, p. 40); 4) self-forgetfulness (Csikszentmihalyi, 1977, p. 42); 5) in control of his action and the environment (Csikszentmihalyi, 1977, p. 44); 6) coherent, noncontradictory demands for action and clear, unambiguous feedback (Csikszentmihalyi, 1977, p. 46); 7) need no goals or rewards external to itself (Csikszentmihalyi, 1977, p. 47). Among them, 4) self-forgetfulness (Csikszentmihalyi, 1977, p. 42), that is, 'concentration' was chosen for the purpose of this study. This will be explained further in section 3.4 Reliability. Consequently, the statement which represent concentration, 'During the Japanese class, I have even temporarily forgotten my problems' in the questionnaire. Students were asked to choose and tick either 'often', 'sometimes' or 'never' as the frequency for their answer.

\subsection{Participants}

Imperial College London's IWLP is called Imperial Horizons. More than 4,000 undergraduate students enrolled in Imperial Horizons in the academic year 2014-15 which is almost half of the undergraduate population. Imperial Horizons offers four areas of study to undergraduate students, i.e. languages and global citizenship, business and professional skills, global challenges and science, culture and society. Language and global citizenship offers ten languages including Japanese. A total of approximately 300 undergraduate students were studying Japanese as either a credit or non-credit bearing basis in four levels (between level 1, which is complete beginners and level 4 being more advanced) and the majority of students take Japanese as a non-credit bearing basis. The courses were taught for two-hours on a weekly basis for 19 weeks (Year 1 students) or 20 weeks (Year 2, 3 and 4 students).

The total number of participants was 48, which consisted of three classes of two language levels Imperial Horizon's level 1 class (16 students) and two Imperial Horizon's level 2 classes (13 students and 19 students) who were all STEM students.

\subsection{Procedure}

The questionnaires was administered and collected in the teaching week W18 for Year 1 students and W19 for Y2, 3 and 4 students. The reason why W18 and W19 was chosen was due to the final exam held in W19 and W20.

A letter to the students which explains the research intentions was composed by the researcher. This letter along with the participation information sheets and the students' consent forms were given to the students on W18 or W19. Students' consent forms were obtained prior to the researcher questionnaire on W19 or W20. Permission to conduct this research was granted by the Director of the Centre for Languages, Culture and Communication before the commencement of the research.

\subsection{Reliability}

Csikszentmihalyi's definition of flow suggests that it is difficult for the participants to judge their own flow state that they experience. Therefore, asking the study's participants if they experience flow may not bring reliable results. If a participant experiences one or more of 
these six elements, it may be possible to say that he/she experiences flow state. For this reason, one of Csikszentmihalyi's (1977) elements, concentration, was chosen and included in the questionnaire to assess if the STEM students experience the flow state.

\subsection{Ethical Issues}

The researcher ensured that the research was not detrimental to the class time for the students to learn Japanese and also ensured that students have the right for their voluntary participation and that they have the right to withdraw at any point without penalty and with no financial inducement. The confidentiality and anonymity of the students' record is respected and protected in the research. The privacy of the participants was respected and students' anonymity and data were also protected.

\subsection{Research Questions}

RQ1. Do students experience enjoyment in Japanese language learning?

RQ2. When students experience enjoyment in learning, do they experience either trait emotion or state emotions, or both? Do they also experience HAP or LAP?

RQ3. Do students experience flow during Japanese lessons?

\section{Results}

\subsection{Enjoyment in Japanese Learning}

Students' enjoyment in the RQ1 was investigated by a) a direct question, 'Is learning fun?' and b) an indirect question, 'Do you wish to continue learning Japanese after this course? If so, why do you think so?' 47 STEM students (out of 48) ticked 'yes' to the direct question, 'Is learning fun?' Only 1 student ticked between 'yes' and 'no' to the statement 'learning is fun'. The result of the indirect question shows that 43 STEM students (out of 48, 90\%) answered that they wished to continue learning Japanese. 5 STEM students (out of 48, 10\%) answered that they do not wish to continue learning Japanese. From the results of direct and indirect questioning, it is possible to say that over $90 \%$ students experienced enjoyment in Japanese language learning.

Furthermore, some STEM students clearly stated in the open-ended questions that they enjoyed the class. STEM students were also asked to provide a reason. Six students answered that "I enjoyed the class" or "I like it". This also shows their enjoyment of Japanese learning based on Blunsdon, Reed, and McNeil (2003) definition of enjoyment, that is, "enjoyment is sometimes called... 'expressed liking” (Blunsdon, Reed \& McNeil, 2003, p. 44). Related to this, two students described the intensity of their liking as "really, enjoyed the course. I fall in love with the language" and "I'm hooked". The content analysis explains the meaning of 'fallen-in-love with the language' as follows: "Japanese is unique. It sounds like a European language (easier to pronounce compared to Arabic and Chinese, but still 'looks' beautiful/nice (non-Latin script)".

From the content analysis, enjoyment is strongly linked to mental states such as 'fun' and 'interesting'. One student made a comment: "Fun + interesting + uses new parts of my brain". 
Although it is claimed that "all learning is accompanied with pain" (Davidson, 1990, p. 201) and "schools, offices, factories are organised around the assumption that the serious work is grim and unpleasant" (Csikszentmihalyi, 1977, p. 1), the majority of STEM students considered that Japanese language learning was enjoyable rather than grim, painful and unpleasant. This may be because STEM major students do not study Japanese as their major subject and they may consider language learning as recreation relaxation or a change from their main studies. Among the 5 STEM students who answered that they did not wish to continue learning, one student answered that "I don't know whether I can handle the stress" which indicates that there was a student who considers that learning was grim, painful and unpleasant.

\subsection{Trait Emotions and State Emotions}

With regards to whether students consider that enjoyment is specific class or cumulative experiences in RQ2, students were asked to tick either statement a) the enjoyment of Japanese was the experience of a specific class or statement b) the enjoyment of Japanese was the cumulative experiences, built over time. 7 STEM students (out of 47 students, 15\%) ticked the statement "the enjoyment of Japanese was the experience of a specific class" which is a state emotion. On the other hand, 40 STEM students (out of 47, 85\%) ticked the statement that enjoyment of Japanese was the cumulative experiences, built over time. This suggests that enjoyment of Japanese language learning may be a result of cumulative experiences rather than the enjoyment of each class.

\subsection{HAP and LAP}

With regards to whether students experienced HAP or LAP in RQ2, students were asked to tick the applicable emotions they experienced from the list of emotions which belongs to HAP or LAP. HAP is associated with emotions such as "enthusiastic, excited, energetic" (Tsai, Knutson \& Fung 2006, p. 290) and "joy” (Kuppens, 2008, p. 1054). LAP was associated with emotions including "calm, relaxed, serene" (Tsai, Knutson \& Fung 2006, 290), "content" (Kuppens, 2008, p. 1054) and "at ease" (Kuppens, 2008, p. 1057). The results showed that "excited and enthusiastic" (65\%, HAP associated emotion) is the most strongly experienced state, followed by "pleasant" (63\%, LAP associated emotion), "comfortable" (58\%, LAP associated emotion), "relaxed" (48\%, LAP associated emotion), "energetic" (44\%, HAP associated emotion). It seems that there are more LAP associated emotions among the STEM students, but this may be explained that the majority of STEM students were undergraduate students who came from collectivist countries. Although dominant states are LAP associated emotions, the first (excited and enthusiastic, 65\%) is HAP, which is preferred by individualist culture. This indicates that "excited and enthusiastic" may be universal emotion regardless of being in individualist or collectivist cultures.

\subsection{Students' Flow Experience}

To investigate RQ3, students were asked to choose the frequency of the following statement: "During the Japanese class, I have temporarily forgotten my problems" were applicable for them. 60\% STEM students ticked 'sometimes', 21\% STEM students ticked 'often' and 19\% 
STEM students ticked 'never'. Those who ticked either 'often' or 'sometimes' are considered to experience flow. Therefore, $81 \%$ STEM students of this study experienced flow states.

In addition, content analysis is also contributed to a STEM students' description of flow experience. A student described her flow experience as follows: "When I study Japanese, I enjoy learning a new language and forgetting about my research and problems". This student's flow experience is very similar from Csikszentmihalyi's (1977) description of a basket player's flow experience: "Sometimes on court, I think of a problem, like fighting with my steady girl, and I think that's nothing compared to the game. You can think about a problem all day but as soon as you get in the game, the hell with it!" (Csikszentmihalyi, 1977, p. 41).

Some students' reasons to continue learning Japanese overlaps with the flow's growth principle. Eleven STEM students' reasons were 'further improvement' such as "I wish to improve" / "My Japanese is not satisfactory" / "I try to get better". Similarly, 10 students answer that reason as "I wish to become more fluent" / "I'm not there yet" / "little has learned" or "I want to learn more". This mirrors one student's answer from a report on Japanese studies survey conducted by Japan foundation in 2016. One of their questions asked what students find most enjoyable about their current Japanese studies course. To answer this question, one student's comment was: "being able to make a noticeable improvement in my knowledge of the Japanese language and understanding of Japanese culture as I continue to study" (Japan foundation, 2016, p. 206). Enjoyment was experienced after students evaluated that they made improvement in their learning. Students' enjoyment is with the presence of flow, therefore, it may be possible to conclude from the result of this study that flow is antecedent of enjoyment.

\section{Discussion and Conclusion}

The results of this study suggest three implications. Firstly, it is possible to change the general assumption in learning from negative (grim and unpleasant or accompanying pain to enjoyment) to positive (enjoyable). The results of the questionnaire shows that the majority of students enjoyed studying Japanese and some students experienced flow and other states such as "fun" or "interesting", "excited and enthusiastic" (HAP emotions) and "relaxed" and "comfortable" (LAP emotions). This leads to the second implication for the language teachers. If language teachers were able to manipulate and invoke flow among their students, students will consider language learning the same as leisure activities such as games, shopping or hobbies. In fact, Japanese language learning can become hobby as one STEM student answered that Japanese is his "hobby" in the questionnaire. This leads to the third implication for the language teacher's professional practices. Language teachers should be informed and be familiar with the concept of enjoyment and flow so that they can manipulate and invoke flow among students. If the majority of language teachers were successful to invoke their students' enjoyment, it will not be long before the day will come when language learning will be established the same status as games and shopping, then language learning becomes more popular and promoted than ever before.

To answer the question of the title of this paper, that is if enjoyment is still important in the 
second language education at university level, this study suggests that enjoyment is important in the second language education at university level.

As for limitation, the generalisation of the findings of the study may be limited. Since the findings of this study are the result of specific participants (IWLP, STEM students in a Japanese language learning context), it may not to be able to generalise for other languages or Japanese learning in other countries. However, it is hoped to uncover students' true enjoyment.

With regards to the suggestion of future research, similar studies in different languages other than Japanese may be of interest as a comparative study. This type of future research may also contribute to change in people's general assumption on language learning to a positive one and to disseminate more successful language teaching and learning, incorporating enjoyment.

\section{References}

Ajzen, I. (1991). The theory of planned behaviour. Organizational Behavior and Human Decision Process, 50(2), 179-211. https://doi.org/10.1016/0749-5978(91)90020-T

Association of University Language Centre (AULC). (2016). UCML-AULC survey of Institution-Wide Language Provision in universities in the UK (2015-2016). Retrieved from http://www.aulc.org/documents/UCML_AULC_2015-2016.pdf

Blunsdon, B., Reed, K., \& McNeil, N. (2003). Experiential Learning in Social Science Theory: An investigation of the relationship between student enjoyment and learning. Journal of Further and Higher Education, 22(1), 93-56. https://doi.org/10.1080/0729436032000056544

Csikszentmihalyi, M. (1977). Beyond boredom and anxiety (2nd ed.). San Francisco: Jossey-Bass.

Davidson, T. (1990). The history of education. London: Archibald Constable.

Fishbein, M., \& Ajzen, I. (1975). Belief, Attitude, intention, and Behavior: An introduction to Theory and Research. Reading, MA: Addison-Wesley.

Goetz, T., Nathan, C., Hall, A. C., Frenzel, A., \& Pekrun, R. (2006). A hierarchical conceptualization of enjoyment in students. Learning and Instruction, 16, 323-338. https://doi.org/10.1016/j.learninstruc.2006.07.004

Japan Foundation. (2016). Japanese studies survey 2015 - A survey of Japanese studies at university level in the UK. London. Retrieved from http://www.jpf.org.uk/download/Japan-Foundation-Japanese-Studies-Survey-2015-Report.pdf

Koufaris, M. (2002). Applying the technology acceptance model and flow theory to online consumer behaviour. Information Systems Research, 13(2), 205-223. https://doi.org/10.1287/isre.13.2.205.83

Kuppens, P. (2008). Individual differences in the relationship between pleasure and arousal. 


\section{Macrothink}

Global Journal of Educational Studies

ISSN 2377-3936 2017, Vol. 3, No. 2

Journal of Research in Personality, 42, 1053-1059. https://doi.org/10.1016/j.jrp.2007.10.007

Lumby, J. (2011). Enjoyment and learning: Policy and secondary school learners' experience in England. British Educational Research Journal, 37(2), 247-264. https://doi.org/10.1080/01411920903540680

Neumann, R., Parry, S., \& Becher, T. (2002). Teaching and learning in their disciplinary context: A conceptual analysis. Studies in Higher Education, 27, 405-417. https://doi.org/10.1080/0307507022000011525

Riber, L. P., \& Noah, D. (2008). Games, simulations, and visual metaphors in education: Antagonism between enjoyment and learning. Educational Media International, 45(2), 77-92. https://doi.org/10.1080/09523980802107096

Robson, C. (1993). Real World Research. Oxford: Blackwell.

Shernoff, D. J., Csikszentmihalyi, M., Schneider, B., \& Shernoff, E. S. (2003). Student engagement in high school classroom from the perspective of flow theory. School Psychology Quarterly, 18(2), 158-76. https://doi.org/10.1521/scpq.18.2.158.21860

Tsai, J. L., Knutson, B., \& Fung, H. (2006). Cultural Variation in Affect Valuation. Personality Processes and Individual Differences, 90(2), 288-307. https://doi.org/10.1037/0022-3514.90.2.288

Young, P. (2010). Generic or discipline-specific? An exploration of the significance of discipline-specific issues in researching and developing teaching and learning in higher education. Innovations in Education and Teaching International, 47(1), 115-124. https://doi.org/10.1080/14703290903525887

\section{Copyright Disclaimer}

Copyright for this article is retained by the author(s), with first publication rights granted to the journal.

This is an open-access article distributed under the terms and conditions of the Creative Commons Attribution license (http://creativecommons.org/licenses/by/3.0/). 